\title{
Perspectives on Intergenerational Vulnerability for Adolescents Affected by HIV: An Argument for Voice and Visibility
}

\author{
Jerker Edström and Nichola Khan
}

\begin{abstract}
The authors address the dynamic role of adolescents affected by HIV and AIDS. They analyse evidence for how intergenerational dynamics interact with HIV-related vulnerability, through the likely influence of being AIDS-affected on vulnerability to HIV infection, and through intergenerational reproductions of structural disadvantages and social determinants of HIV vulnerability. They review evidence of AIDS' impacts on children and of contextual influences on their vulnerability to infection, linked to orphaning, inequality and lack of education. They point to the paucity of longitudinal research into this area and challenges in uncovering structural determinants of vulnerability. Pressure for generalised 'hard' evidence in global policy fails to capture context-specific dynamics. Focus shifts from the notion of children as passive 'objects' of study to one that includes 'agency' as central to adolescents maturing and interacting with multiple challenges. The authors argue for new approaches to research and policy, giving children voice and visibility in these debates.
\end{abstract}

\author{
1 Introduction \\ What has the HIV epidemic got to do with \\ intergenerational processes, or transmissions? \\ Since its beginning, the epidemic has been closely \\ associated with sex and death and tied to the \\ cycle of human reproduction. Over the first \\ quarter of a century of AIDS, several generations \\ of children affected by HIV and AIDS have been \\ born, many of them orphans. Many of these \\ children have gone on to become infected by HIV \\ themselves. Actual data on HIV infections in \\ children are hard to come by, however, partly \\ because standard WHO and Joint United Nations \\ Programme on HIV/AIDS (UNAIDS) data on \\ HIV-positive 'children' typically excludes all \\ children between 15 and 18 years; that is, those \\ children who are more likely to become infected. \\ Figures on children in that age group are instead \\ subsumed under categories for broader age \\ groups beyond children, referred to as 'adults', \\ despite the almost universal agreement in the \\ Convention on the Rights of the Child that all \\ people under the age of 18 years are children
}

(UN 1989). UNAIDS (2008) reports on one such category, 'young people', indicate that 45 per cent of all new infections occur in the age group 15 -24 years. This certainly suggests that children and the transition to adulthood may be quite central to the dynamics of the HIV epidemic itself. Part of the reason for this inconsistency in how we think of children and AIDS lies in a 'tradition' among practitioners and policymakers of only reporting on children as 'affected' by AIDS, or on those orphaned.

Many policies and programmes for orphans and vulnerable children (OVG) or children affected by HIV/AIDS (CABA) have been developed to 'mitigate' impacts of AIDS and poverty for young children (UNAIDS and UNICEF 2004; Foster $e t$ al. 2005). Many, if not most, fail to recognise that many of these children are adolescents who need skills and means to protect their sexual and reproductive health as well as their longer-term personal prospects. This aspect is typically omitted from OVG policies and programmes,

IDS Bulletin Volume 40 Number 1 January 2009 (c) 2009 The Author(s). Journal compilation (C) Institute of Development Studies Published by Blackwell Publishing Ltd, 9600 Garsington Road, Oxford OX4 2DQ, UK and 350 Main Street, Malden, MA 02148, USA 
since sexuality is often said to be too sensitive a topic for local communities and is avoided by certain donors, for political expediency.

Adolescent children living in households affected by HIV and AIDS are often deeply affected, poor and socially isolated. They may be some of the most vulnerable to HIV infection among adolescents, embodying an intergenerational process of reproduction of the epidemic itself. Thus, a key question is 'what is the evidence that children affected and made vulnerable by the impacts of AIDS grow up with compromised sexual wellbeing or heightened vulnerability to HIV infection?' Further, 'how do poverty and social marginalisation modulate such processes in adolescent development and influence transmission of the epidemic?' The short answer to these questions is that we actually know fairly little, because we have not been tracking it closely. This article draws on some recent research and reviews ${ }^{1}$ to explore how we could come to understand the interlinkage between cycles of HIV transmission, sexual development and transitions to adulthood. First, we need to delineate a more focused scope, by drawing a few conceptual distinctions.

\section{Situating intergenerational 'transmissions'}

In this article we want to consider potential HIVrelated intergenerational processes in young people and their role in reproducing conditions of vulnerability and risks of HIV infection. We recognise the likely existence of macro-level dynamics related to long-wave crises or stresses in certain societies hit hard by HIV and AIDS such as via the broader economy, or medium- and long-term viral-level dynamics These are important in clarifying the broader context within which intergenerational cycles evolve. However, the focus of this article is primarily on evidence for personal and social-level issues of HIV-related vulnerabilities of young people, particularly those affected by the virus.

We distinguish conceptually between the crossgenerational transmission of the virus itself and the intergenerational reproduction of vulnerabilities, disadvantaging children and adolescents in a multitude of situations. The former is more clearly about specific threats from particular adults than about relative vulnerabilities or the resilience and agency of children. They include transmission from mothers to their embryos or infants (in utero, perinatally or through breast milk). This former category also includes transmission of the virus from adults to children, often adolescents, such as through adult-adolescent sex or shared needles or syringes. There is also the relatively unexplained and unexplored issue of children aged 2-14 years becoming infected, which may relate to both child sexual abuse by adults and transmission directly between children. ${ }^{2}$

Our focus in this article is on the

intergenerational production, or reproduction, of vulnerabilities and resilience to HIV (as opposed to 'of the virus'). This is more related to dynamic processes of child development and socialisation, within contexts of broader social and economic development, shaping the life chances, degree of agency and empowerment of adolescents in sexual and other areas of life. Again, this can be broken down into two major areas:

The intergenerational influence on HIV vulnerability from becoming affected by HIV or AIDS (such as from infection, illness and/or premature death of parents or other carers) translating into heightened vulnerability to HIV infection.

- Intergenerational reproductions of structural disadvantages and social determinants of HIV vulnerability (whether or not the child is affected by HIV).

As longitudinal research that tracks evidence for these kinds of dynamics over childhood and transitions to adulthood is scarce, we briefly discuss some potted evidence and reviews of evidence of children becoming affected or disadvantaged by HIV and AIDS in economic, educational, gendered and other social domains. We consider some evidence for disadvantages in these areas and their role in increasing adolescents' and young people's vulnerability to HIV and other sexually transmitted infections (STI).

The discussion points to some contextual and individual sources of HIV-related vulnerability that may be most directly related to intergenerational processes. It highlights areas where there is some evidence that children affected by HIV and AIDS appear relatively worse off than other children, as well as whether disadvantages in these areas appear to be associated with vulnerability to infection by HIV, or 
other proximate factors like risk behaviours. ${ }^{3}$ It discusses some key findings with reference to young people's levels of visibility and voice in HIV policy debates, and concludes with some proposals for research, policy and programmes.

\section{Impacts of AIDS on children: orphaning, psychosocial, economic and educational}

The effects of HIV and AIDS on children have been well documented. These relate to the death or ill health of parents or carers, economic constraints, compromised access to education and stigma associated with the disease.

The orphaning of children has significantly increased in the hardest hit countries, as a result of HIV. UNICEF (2007) reported an estimated 132.7 million orphans ( $0-17$ years) from all causes worldwide in 2005, and out of these some 15.2 million were thought to have lost one or both parents to AIDS, which represents around 11 per cent of all orphans. In sub-Saharan Africa (accounting for some 90 per cent of these orphans to HIV), this proportion exceeds 25 per cent and can be higher in the highest prevalence countries. These figures have steadily increased from less than 1 million to circa 12 million in subSaharan Africa between 1990 and 2007 (UNAIDS 2008). With the scale-up of antiretroviral treatment (ART), however, this increase is expected to level off and start to decline over the next few years (ibid.).

The effects of orphaning on children can be serious and long lasting. In a review of the mental health of children orphaned by AIDS in sub-Saharan Africa, Cluver and Gardner (2007) found that internalising problems were common and that HIV-orphaned children had clinic-level psychiatric disorders at rates well above nonorphans or other orphans. See also studies showing negative psychological impacts on AIDSorphaned children in South Africa by Cluver et al. (2007, 2008). These may well translate into greater vulnerability to HIV infection as children grow up, as discussed below.

Children who are affected by HIV and AIDS are often also compromised in terms of broader wellbeing, including economically. Reviews of a wide range of studies in sub-Saharan Africa since the early 1990s report that households in Africa are often economically vulnerable to the impacts of AIDS, by the disease depleting human and other resources that households employ in livelihood strategies, particularly in agriculture (e.g. Gillespie 2006; Edström and Samuels 2007).

Labour shortages arise from sickness and premature adult deaths, as well as from competing time-demands arising from, for example, the need to nurse the sick. At the same time, assets (such as savings and working capital investments) are often converted to cash in order to meet medical costs. These impacts vary depending on contexts, households and their livelihood strategies, but the welfare consequences for children tend to be typical. They include increased household chores, pressures for child labour or income generation (including child prostitution), increased care for ill adults and decreased school participation. In a broad review of evidence from low prevalence settings in different continents, the Quality Assurance Project (QAP et al. 2008) also found that HIV-affected households, especially female-headed ones, tend to be worse off than unaffected households. They also found that, as a consequence, children have increasing socioeconomic responsibilities, but the effects on their lives are mixed.

The evidence of the impact on the food security and nutrition of children is mixed, however, and is strongly related to particular contexts and caring arrangements (Gillespie 2006). Furthermore, there is very limited evidence that nutritional disadvantage significantly affects vulnerability to infection as children grow up. While context varies and while evidence on nutritional level impacts is mixed, we can say that children orphaned by AIDS, and many others living with adults ill with HIV, do end up growing up in greater poverty than other children.

An important and partly related disadvantage facing many orphans and children affected by HIV is that of compromised opportunities for, or participation in, education. Evidence from household surveys in 56 countries suggests that orphans who have lost both parents are some 12 per cent less likely to attend school than other children (UNAIDS 2008), although educational differentials in some of the most affected countries are lower and trends suggest that several of these countries are reducing educational disparities seen earlier in the epidemic (ibid.). Participation in school, access and progression to upper grades are often compromised in different ways from being 
affected by HIV and AIDS (Bärnighausen $e t$ al. 2007; Case and Ardington 2005; Campbell et al. 2008; Edström et al. 2008a). More girls drop out of school to perform caring roles, while more boys drop out to engage in income generation or child labour (Steinberg et al. 2002). Although evidence on the role of orphanhood on enrolment is mixed overall across countries and regions, older affected children in particular appear less likely to be enrolled in and to attend school than their unaffected peers (QAP et al. 2008). While children affected often drop out of school because of economic factors, this is not always because of the cost of schooling. Furthermore, several studies show that many children and their carers fear discrimination from schoolteachers, peers and the community (ibid.). The link between economic hardship and education appears to play a big role and factors such as education are thought to be central to reducing children's vulnerability to HIV as they grow up, as discussed below.

\section{Contextual influences on adolescents' vulnerability to infection: orphaning, inequality and lack of education}

In this section we discuss some evidence for the impacts of HIV and AIDS on orphaning, psychosocial wellbeing, education and relative wealth and their influence on children's vulnerability to HIV infection. This evidence is typically not directly traceable to being affected by HIV, but often suggests plausible pathways for intergenerational processes. Much of the evidence does, however, relate to orphans, many of whom are HIV orphans in sub-Saharan Africa, as we have seen.

\subsection{Orphaning}

A recent review for the Joint Learning Initiative on Children and HIV/AIDS (JLICA) by Gluver and Operario (2008) found four studies reporting on a higher prevalence of HIV status among orphans (particularly female orphans), including three from Africa - a national study in South Africa and two in Zimbabwe (Operario et al. 2007; ${ }^{4}$ Gregson et al. 2005; $;{ }^{5}$ Birdthistle et al. 2008). ${ }^{6} \mathrm{~A}$ fourth study (Kissin et al. 2007) of street youth aged 15-19 in St Petersburg, Russia, found that double orphans were over three times more likely and single orphans almost two times more likely than non-orphans to be HIV-positive. If studies on the direct link from orphaning to HIV infection are few and far between, they found relatively more research and a stronger base of evidence on higher rates of sexual behaviour among orphans than among other children. For example, the two studies from Zimbabwe found that female orphans were also more likely to have experienced other STI symptoms. Several crosssectional studies from South Africa, Kenya and Zimbabwe report that orphan children are more likely to have had sex than non-orphans (Thurman et al. 2006; Operario et al. 2007; Juma et al. 2007; $;^{7}$ yamukapa et al. 2008). In a national household survey of South African young people, Operario et al. (2007) found female orphans to be more likely to have had multiple sex partners than female non-orphans. Furthermore, evidence of earlier sexual debut among orphans than nonorphaned children is provided by two recent reviews of Demographic and Household Survey (DHS) data sets from Lesotho, Malawi, Mozambique, Rwanda and Tanzania (Campbell et al. 2008) $)^{8}$ and from Lesotho, Mozambique, Tanzania and Uganda (Palermo and Peterman 2008). The former of these also found that double orphans were more likely than any other group to have had an earlier sexual debut, and more so in urban areas. In addition to displaying higher sexual vulnerability than other children, orphans in the Kenya study by Juma et al. (2007) reported significantly lower condom use in their last sexual encounter than non-orphans, and orphaned girls were slightly more likely to report having had transactional sex. Early and unprotected sex has also been reported to be higher among orphaned than non-orphaned adolescents in the USA (Hudis 1995).

The sexual risk and vulnerability of orphans appears to be gendered by the sex of both the orphan and the deceased parent. Juma and colleagues (2007) found female maternal orphans in Kenya to be considerably more likely to have had sex than girls whose mothers were alive. Hallman (2004) reports on findings from KwaZulu-Natal, South Africa, where paternal deaths appear to influence the sexual vulnerability of female as well as male orphans. Parental death of either gender was associated with earlier sexual debut for girls, whereas for orphaned boys, the death of a father - but not a mother - was associated with subsequent earlier sexual debut than for other boys, with other factors controlled for (Hallman 2008b).

There are many reasons why orphans may be sexually more vulnerable than other children. 
Orphaning has been associated with psychological stress (as discussed), but also with low perceived self-efficacy, along with feelings of lack of control over sexual health and riskier sexual behaviours (Gregson et al. 2004). Furthermore, positive and supportive interaction between parents and children has been associated with children's later debut of sexual activity as well as lower sexual risktaking in developing countries (Babalola et al. 2005; Marques and Ebrahim 1991). In a review of social and economic determinants of young people's vulnerability to HIV, Hallman (2008c) describes a range of studies showing that, with some exceptions, the sexual vulnerability of girls in particular is mitigated by social capital, or participation and inclusion in local groups, as well as more supportive and cohesive local environments. These findings suggest that both relationships with parents or carers and relationships with peers, in the social sphere beyond the home, are crucial in children developing autonomy and resilience in their sexual lives.

\subsection{Inequalities}

As discussed above, children orphaned or otherwise affected by HIV and AIDS (such as living with ill relatives or carers) often experience a decline in socioeconomic conditions. Poverty itself has often been associated with vulnerability to HIV infection in different ways in the literature. We need to be cautious in this, however, as the relationships are complex, and there are no correlations between absolute poverty and HIV prevalence at national levels in sub-Saharan Africa, for example, although the association between HIV and income inequality is quite strong (Gillespie et al. 2007; Gillespie 2008). There is also more disaggregated data and a wealth of evidence that relative poverty in the context of inequality and urbanisation can increase risk behaviours and raise the odds of contracting HIV - particularly for young females (Hargreaves et al. 2002; Machel 2001; Rwenge 2003). Rather than absolute poverty, it is the 'inequalising' and destabilising effects of global economic development, with its concomitant increasing wealth gaps, mobility of people and goods and resultant breaks with tradition, along with the new opportunities and aspirations created by wealth disparities, which combine to exponentially multiply human (and viral-human) interactions. Evolving combinations of disadvantage create synergistic effects, and Hallman (2008a), for example, points to the combination of relative poverty and orphaning as a particularly strong combination for increasing the sexual vulnerability of adolescent girls.

\subsection{Lack of education}

Being affected by HIV and AIDS in their families or households tends to affect children's access to education and increase the risks of older children dropping out of school. In analyses of cross-country data from demographic and health surveys, Lloyd finds that adolescent girls out of school are more vulnerable to sexual and reproductive health risks (2007). Education can not only delay age of marriage (marriage being a major risk factor for HIV for young women in Africa), it can also provide adolescents with skills, knowledge and understanding of sexual risk, as well as provide sources of peer support and social capital. Formal education often fails to contribute its fuller potential in terms of enabling young people with knowledge and skills in sexual and reproductive health, by avoiding the topic or peddling unproven and apparently ineffective approaches to 'teaching' abstinence (Lin and Santelli 2008). While such curricula and approaches have not been shown to be effective, more comprehensive ways of teaching adolescents, providing different options and factual information, have been shown to be effective in many cases (Kirby 2008). The role of education within intergenerational dynamics of HIV appears to be potentially significant, as is its woefully untapped role in interrupting transmissions. There is a need to test the influence of personal shocks, for example orphanhood and the loss of carers, economic hardships/inequalities, social capital or inclusion as well as educational attainment.

\section{Discussion}

A basic problem with our vision for children and AIDS is a pervasive tendency to focus on vulnerability and on children as affected by HIV and AIDS. Accordingly, our frameworks and representations of children convey them as entirely passive and lacking agency. Furthermore, blinkered by the limitations of statistics and reporting on children and HIV, and inconsistencies in reporting definitions of age groups, key adolescent groups have become invisible in policy. We continually find it challenging to contemplate and represent children at the same time, as affected by crises and as being or becoming sexually active and at risk of HIV, STIs or pregnancy. 
However, extensive scanning of various reviews and studies on these topics reveals a vast tapestry of variegated gradations of hard-to-soft, quantitative and qualitative, or social, economic, anthropological, epidemiological and psychological evidence. Much is becoming understood, but far more remains speculative, if plausible. This tapestry provides plenty of 'circumstantial evidence' suggestive of intergenerational dynamics of reproducing vulnerabilities and opportunities for infection, but hard evidence - of the kind considered 'gold standard' in public health policy - is very hard to come by in matters involving structural determinants and complex local processes driving transmission (Gupta et al. 2008). This is particularly rare for processes which unfold across generations and which also involve multiple influences on child and adolescent development.

Longitudinal approaches are probably underprioritised and they could certainly play a key role in establishing causal 'mechanisms' in many settings, or at least provide stronger explanations. However, we need to ask how realistic an ambition of longitudinal data collection might be as our main guide to action and policy in this area. Or rather, while research must progress, the human costs of 'holding off' on finding 'hard proof' for much longer appear unacceptable. Thus, we need to craft better policies by combining what is known in more informed and consultative ways. One might also expect a limit to how many variables can be usefully tracked and controlled for without making studies and surveys so large and costly as to make them a poor investment. One dilemma in processes involving dynamics in different domains is the fact that complex interactions across multiple dimensions are often highly context-specific, making it harder to generalise findings.

Realities vary depending on place and whose concerns are at stake. A fundamental constraint is a common assumption that we can establish truly explanatory general models of causal pathways for these processes. Our 'objects' of analysis are people with evolving capacities for agency and autonomous decision-making, with voices of their own, whether heard or not. The active role in outcomes of the subjective perceptions of young people involved in the behaviours of concern here (such as exploratory, recreational or other types of sex or stimulant use) makes accurately describing and measuring processes and changes a genuine challenge, as do the unpredictably shifting social cultures and peer norms influencing their oscillating perspectives. The scope for 'objective measurement' may be limited here and a key question becomes 'whose evidence counts?' in the often-quoted words of Robert Chambers (1995). The seemingly obvious answer, becomes 'the evidence and voices of children and youths should count for a lot more', although the subsequent retort of 'how?' may be harder to answer in a simple way.

Without suggesting that children will necessarily lead such research, more open-ended frameworks and processes for enquiry, coupled with more flexible and interactive methods for engaging young researchers, with greater accessibility of expert knowledge by young people, will almost certainly be required if we are to empower adolescents with the tools and other means they need to play a fuller role in research into their development.

With so little research that gives voice to the concerns and realities of the children most centrally involved in the cycles of transmission in this epidemic, it is not surprising that the most vulnerable and active children remain all but invisible in policy on AIDS. To the extent that they are seen, they are usually stereotyped in very broad or abstract character. If the history of successful responses to AIDS has taught us anything new to date, one key lesson is that it is often the action, resistance and response from those affected on the margins that changes the dynamics and course of the epidemic - precisely in response to the stigma, inequity, divergence and global aspirations which accompany the context of the epidemic and various official responses. So, why are adolescents' issues so rarely seen as a priority in policy on AIDS?

While social groups are important to adolescents' agency and resilience to HIV, such groups are typically not organised on the basis of sexual health. Furthermore, there are few obvious forms of social organisation for the most vulnerable and at risk children, short of 'gangs'. For those growing up in contexts of risk, such as children of sex workers or people injecting drugs, inclusion of their issues in the agendas of marginalised adults is compromised by issues of legality, which are particularly heightened with 
regards to child protection concerns. Genuine child participation in actual policy processes for children appears to be rare (Edström et al. 2008b; Budlender et al. 2008; Mamdani et al. 2008). Givil society organisations working on children's rights or other issues can play a key role in giving visibility to children's concerns. For the right children and adolescents to become visible and be given voice, it is essential that child rights organisations and progressive government actors build alliances with civil society groups of populations most vulnerable and key to the epidemic, as well as particular youth groups, to create spaces for engagement and joint learning.

\section{Conclusions}

The key groups of adolescents and older children are missed and excluded from policies and programmes that could empower them to break the cycles of transmission of HIV. This stems from a legacy of a disjointed and blinkered vision of children in relation to sexuality, which has in recent years been further compromised by conservative policies that have disregarded evidence in favour of a conservative moral vision of family values, and which has likely cost many young lives. Adolescents are a major and especially vulnerable proportion of vulnerable children, and there is evidence that those affected by HIV, AIDS or other similar personal crises appear particularly vulnerable sexually. Given the potential of HIV-related stigma to compound such crises, we should not target children on the basis of 'AIDS orphanhood' in programmes or policy, but we nevertheless do need to identify the most vulnerable children within local and national contexts. We need to develop sophisticated ways to link up social protection, child protection and HIV prevention (or sexual and reproductive health more broadly), with solutions sensitive to particular impacts and dynamics of HIV involving children.

A clear recommendation from a wealth of strong evidence is the injunction to invest particularly in adolescent girls'schooling, which is shown to mitigate girls' vulnerability, but we also need to ensure that strong and comprehensive HIV, sexual and reproductive health education is delivered to children sufficiently early and consistently in school. Policies to strengthen the quality and coverage of education should be accompanied with an emphasis on strategies for including those excluded, among them children affected by HIV or similar family crises. Social welfare, child protection and education policies in most affected countries need to be AIDS sensitive in a gendered and age-differentiated way, while based on context-specific/relevant evidence. HIV prevention for adolescents needs to particularly target those most vulnerable to infection, within a context-specific and structural analysis, emphasising social inclusion and linking to education, community action, welfare or child protection as appropriate. The relevant children most vulnerable to infections need to participate in the design of such solutions. By relevant children, we mean those who grow up in contexts of HIV risk, spend their time on the streets or are involved in gangs, but also a range of other children made vulnerable in their daily strategies for gaining access to education, resources, entertainment or social inclusion.

Because of the role of sex in the human reproductive cycle, and the peaks of interactions and risks associated with transitions to adulthood, these dynamics are at the same time intergenerational and deeply gendered. Bias towards certain kinds of evidence for policy usually fails to capture complex and locally diverse structural influences on HIV transmission - let alone longer-term intergenerational dynamics - and connectedly fail to give voice to the lived experiences of real children growing into young adults. In policy, the visibility of the priority sexual health issues for adolescents at risk (including those affected by AIDS) are compromised for a host of reasons to do with their relative invisibility in official statistics; their relative lack of legal (if not human) rights or representation; or, their own re-interpretations and contestations of handed-down norms and values on gender and sexuality, so uncomfortably challenging to parents, politicians, adult professionals and 'opinion leaders'. 


\section{Notes}

1 These draw on review work carried out for the Joint Learning Initiative on Children and AIDS and published in a recent IDS Bulletin (de Waal et al. 2008; Hallman 2008a; Cluver and Operario 2008), a review for Department for International Development (Edström and Samuels 2007) as well as a report commissioned by UNICEF (Edström and Khan, forthcoming).

2 Globally, the number of children (below the age of 15) living with HIV in 2007 was estimated at around 2.5 million, as compared to some 1.5 million in 2001. Almost 90 per cent of all HIV-positive children live in subSaharan Africa. It is important to note that these figures exclude a large number of children infected in the age groups from 15 up to 18 years (when sexual activity increases

\section{References}

Babalola, S.; Tambashe, B.O. and Vondrasek, C. (2005) 'Parental Factors and Sexual RiskTaking Among Young People in Côte d'Ivoire', African Journal for Reproductive Health 9.1: 49-65

Bärnighausen, T.; Hosegood, V.; Timaeus, I.M. and Newell, M-L. (2007) 'The Socioeconomic Determinants of HIV Incidence: Evidence from a Longitudinal, Population-Based Study in Rural South Africa', AIDS 21. Suppl. 7: S29-S38

Birdthistle, I.J.; Floyd, S.; Machingura, A.; Mudziwapasi, N.; Gregson, S. and Glynn, J.R. (2008) 'From Affected to Infected? Orphanhood and HIV Risk Among Female Adolescents in Urban Zimbabwe', AIDS 22.6: 759-66

Budlender, D.; Proudlock, P. and Jamieson L. (2008) 'Formulating and Implementing Socioeconomic Policies for Children in the Context of HIV/AIDS: South African Case Study', IDS Bulletin 39.5

Campbell, P.; Handa, S. et al. (2008) 'A Situation Analysis of Orphans in 11 Eastern and Southern African Countries', draft paper, Nairobi: UNICEF ESARO

Case, A. and Ardington, C. (2005) The Impact of Parental Death on School Enrolment and Achievement: Longitudinal Evidence from South Africa, CSSR Working Paper 97, Cape Town: Centre for Social Science Research, University of Cape Town

Chambers, R. (1995) 'Poverty and Livelihoods: Whose Reality Counts?', Environment and Urbanization 7.1: 173-204 significantly), so significantly underestimate the true number of children infected.

3 We do not directly cover sources of HIV vulnerability linked to more long-term trends, such as urbanisation, marketisation, Christianisation or migration, nor transient external shocks such as floods or conflict/postconflict situations which may mark and affect particular generations, but not necessarily reproduce intergenerationally.

4 A national representative household survey of young people aged 15-24.

5 A population survey of children aged 15-18.

6 A follow-up study of 1,283 girls aged 15-19.

7 A study of 1,200 children aged 10-17 in Kenya.

8 Data on orphans aged 15-17 from Lesotho, Malawi, Mozambique, Rwanda and Tanzania.

Cluver, L. and Gardner, F. (2007) 'Risk and Protective Factors for Psychological WellBeing of Orphaned Children in Cape Town: a Qualitative Study of Children's Views', AIDS Care 19.3: 318-25

Cluver, L. and Operario, D. (2008) 'Intergenerational Linkages of AIDS: Vulnerability of Orphaned Children for HIV Infection', IDS Bulletin 39.5, Brighton: IDS

Cluver, L.; Gardner, F. and Operario, D. (2008) 'Effects of Stigma and Other Community Factors on the Mental Health of AIDSOrphaned Children', Journal of Adolescent Health 42.4: 410-17

Gluver, L.; Gardner, F. and Operario, D. (2007) 'Psychological Distress Among AIDSOrphaned Children in Urban South Africa', Journal of Child Psychology and Psychiatry 48.8: 755-63

de Waal, A.; Edström, J. and Mamdani, M. (2008) 'Introduction: Children, AIDS and Development Policy', IDS Bulletin 39.5

Edström, J. and Khan, N. (forthcoming) Protection and Care for Children Faced with HIV and AIDS in East Asia and the Pacific: Framing the Issues, Responses and Priorities in the Region, IDS report to UNICEF, Bangkok: UNICEF EAPRO

Edström, J. and Samuels, F. (2007) HIV, Nutrition, Food and Livelihoods in Sub-Saharan Africa: Evidence, Debates and Reflections for Guidance, Brighton: IDS, www.livelihoods.org/info/docs/ DFID\%20on\%20AIDS, \%20Food\%20\%20and\% 20Livelihoods.pdf (accessed 16 October 2008) 
Edström, J.; Lucas, H.; Sabates-Wheeler, R. and Simwaka, B. (2008a) A Study of the Outcomes of Take-Home Food Rations (THR) for Orphans and Vulnerable Children in Communities Affected by AIDS in Malawi, Research Report, IDS, REACH, UNICEF WFP, Nairobi: UNICEF ESARO

Edström, J.; Roberts J. and Sumner, A. with Chamreun, C.S. (2008b) 'Policy Process for Children and AIDS in Cambodia: Drivers and Obstacles', IDS Bulletin 39.5

Foster, G.; Levine, C. and Williamson, J. (eds) (2005) A Generation at Risk: The Global Impact of HIV/AIDS on Orphans and Vulnerable Children, New York: Cambridge University Press

Gillespie, S.R. (2008) 'Poverty, Food Insecurity, HIV Vulnerability and the Impacts of AIDS in Sub-Saharan Africa', IDS Bulletin 39.5

Gillespie, S.R. (2006) AIDS, Poverty, and Hunger: Challenges and Responses, Washington, DC: International Food Policy Research Institute

Gillespie, S.R.; Kadiyala, S. and Greener, R. (2007) 'Is Poverty or Wealth Driving HIV Transmission?', AIDS 21. Suppl. 7: S5-S16

Gregson, S.; Terceira, N.; Mushati, P.; Nyamukapa, C. and Campbell, C. (2004) 'Community Group Participation: Can it Help Young Women to Avoid HIV? An Exploratory Study of Social Capital and School Education in Rural Zimbabwe', Social Science and Medicine 58.11: 2119-32

Gregson, S.; Nyamukapa, G.; Garnett, G.P.; Wamba, M.; Lewis, J.J.C.; Mason, P.R.; Chandiwana, S.K. and Anderson, R.M. (2005) 'HIV Infection and Reproductive Health in Teenage Women Made Vulnerable by AIDS in Zimbabwe', AIDS Care 17.7: 785-94

Gupta, G.R.; Parkhurst, J.; Ogden, J.; Aggleton, P. and Mahal, A. (2008) 'Structural Approaches to HIV Prevention', The Lancet 372, August 30: 764-75

Hallman, K. (2008a) 'Researching the Determinants of Vulnerability to HIV Among Adolescents', IDS Bulletin 39.5

Hallman, K. (2008b) 'Orphanhood Type and Sexual Debut: A Panel Study from KwaZuluNatal, South Africa', Economic Development and Cultural Change, under review

Hallman, K. (2008c) 'Social Exclusion: The Gendering of Adolescent HIV Risk in South Africa', in J. Klot and V. Nguyen (eds), The Fourth Wave: An Assault on Women - Gender, Culture and HIV in the 21st Century, Social Science Research Gouncil and UNESCO, under review
Hallman, K. (2004) Socioeconomic Disadvantage and Unsafe Sexual Behaviours of Young Women and Men in South Africa, Policy Research Division Working Paper 190, New York: Population Council, www.popcouncil.org/publications /wp/wplist.html (accessed 16 October 2008)

Hargreaves, J.R.; Morison, L.A.; Chege, J.; Rutenburg, N.; Kahindo, M.; Weiss, H.A.; Hayes, R. and Buvé, A. (2002) 'Socioeconomic Status and Risk of HIV Infection in an Urban Population in Kenya', Tropical Medicine and International Health 7.9: 793-802

Hudis, J. (1995) 'Adolescents Living in Families with AIDS', in S. Geballe, J. Gruendel, and W. Andiman (eds), Forgotten Children of the AIDS Epidemic, New Haven: Yale University Press: 83-94

Juma, M.; Askew, I. and Ferguson, A. (2007) Situation Analysis of the Sexual and Reproductive Health and HIV Risks and Prevention Needs of Older Orphaned and Vulnerable Children in Nyanza Province, Kenya, Nairobi: Department of Children's Services, Government of Kenya

Kirby, D. (2008) 'The Impact of Abstinence and Comprehensive Sex and STD/HIV Education Programs on Adolescent Sexual Behaviour', Sexuality Research E' Social Policy 5.3, Berkley: University of California Press

Kissin, D.; Zapata, L.; Yorick, R.; Vinogradova, E.N.; Volkova, G.; Cherkassova, E.; Lynch, A.; Leigh, J.; Jamieson, D.; Marchbanks, P. and Hillis, S. (2007) 'HIV Seroprevalence in Street Youth, St. Petersburg, Russia', AIDS 21.17: 2333-40

Lin, A.J. and Santelli, J.S. (2008) 'The Accuracy of Condom Information in Three Selected Abstinence-Only Education Curricula', Sexuality Research \& Social Policy 5.3, Berkley: University of California Press

Lloyd, C.B. (2007) The Role of Schools in Promoting Sexual and Reproductive Health Among Adolescents in Developing Countries, Poverty, Gender, and Youth Working Paper 6, New York: Population Council

Machel, J.Z. (2001) 'Unsafe Sexual Behaviour Among Schoolgirls in Mozambique: A Matter of Gender and Class', Reproductive Health Matters 9.17: 82-9

Mamdani, M.; Rajani, R. and Leach, V. (2008) 'How Best to Enable Support for Children Affected by HIV/AIDS? A Policy Case Study in Tanzania', IDS Bulletin 39.5

Marques, N.M. and Ebrahim, G.J. (1991) 'The Antecedents of Adolescent Pregnancy in a 
Brazilian Squatter Community', Journal of Tropical Pediatrics 37.4: 194-8

Nyamukapa, C.; Gregson, S.; Lopman, B.; Saito, S.; Watts, H.J.; Monasch, R. and Jukes, M.C.H. (2008) 'HIV-associated Orphanhood and Children's Psychosocial Distress: Theoretical Framework Tested With Data From Zimbabwe', American Journal of Public Health 98.1: 133-41

Operario, D.; Pettifor, A.; Cluver, L.; MacPhail, C. and Rees, H. (2007) 'Prevalence of Parental Death Among Young People in South Africa and Risk for HIV Infection', Journal of Acquired Immune Deficiency Syndromes 44.1: 93-8

Palermo, T. and Peterman, A. (2008) 'Orphanhood as a Risk Factor for Child Marriage and Early Sexual Debut: Evidence from SubSaharan Africa', draft paper, Learning Group 4, Geneva: Joint Learning Initiative on Children and HIV/AIDS QAP (Quality Assurance Project), USAID, Health Care Improvement Project and UNICEF (2008) The Evidence Base for Programming for Children Affected by HIV/AIDS in Low Prevalence and Concentrated Epidemic Countries, New York: UNICEF

Rwenge, M.J.R. (2003) 'Poverty and Sexual Risk Behaviour Among Young People in Bamenda,
Cameroon', African Population Studies 18.2: 91-104

Steinberg, M.; Johnson, S.; Schierhout, G. and Ndegwaet D. (2002) A Survey of Households Impacted by HIV/AIDS in South Africa: What are the Priority Responses?, Menlo Park, California: Kaiser Family Foundation

Thurman, T.; Brown, L.; Richer, L.; Maharaj, P. and Magnani, R. (2006) 'Sexual Risk Behavior Among South African Adolescents: Is Orphan Status a Factor?', AIDS and Behavior 10.6: $627-35$

UN (1989) Convention on the Rights of the Child, Geneva: United Nations

UNAIDS (Joint United Nations Programme on HIV/AIDS) (2008) Report on the Global AIDS Epidemic: Executive Summary, Geneva: UNAIDS

UNAIDS (Joint United Nations Programme on HIV/AIDS) and UNICEF (2004) The Framework for the Protection, Care and Support of Orphans and Vulnerable Children Living in a World with HIV and AIDS, Geneva and New York: UNAIDS and UNICEF

UNICEF (2007) The State of the World's Children 2008, New York: UNICEF 